\title{
Experimental Study on Failure Mode of Concrete Beams Strengthened with FRP Sheet
}

\author{
Juanxia ZHANG ${ }^{1,2 a^{*}}$, Zhonghui $\mathrm{CHEN}^{1, \mathrm{~b}}$, Xianzhang $\mathrm{GUO}^{2, \mathrm{c}}$ and Wencheng MA ${ }^{2}$ \\ ${ }^{1}$ School of Mechanics and Civil Engineering, China University of Mining and Technology, \\ Beijing,China \\ ${ }^{2}$ College of Resources and Civil Engineering, Northeastern University, Shenyang,China \\ a zhang_juanxia@126.com ${ }^{1}$, bchen_zhong_hui@sohu.com, ${ }^{\text {c }}$ guoxianzhang@126.com
}

\begin{abstract}
The failure mode of the FRP reinforced concrete beam with different sheet length was investigated by experiments. The results indicate that, more cracks distributed on the bottom of the beam in the failure process of the FRP reinforced concrete structure. The effect of the FRP sheet length is considered to be an important factor not only to significantly influence the loading capacity but also to control the maximum deflection of the concrete beam. In addition, the loading capacity is increased and maximum deflection of the concrete beam is also increased with the increasing of the FRP sheet length. It showed that FRP strengthened beams failed prematurely in a brittle and sudden manner due to debonding between FRP and concrete substrate and therefore the full strength of the FRP sheet cannot be sufficiently utilized.
\end{abstract}

\section{Introduction}

FRP composite material was widely used in civil engineering structure reinforcement because of its strong plasticity, corrosion resistance, tensile and fatigue level was being better than the steel composite material. A lot of scientific research work have made by scholars and engineers of civil engineering around the world [1-2]. Externally bonded FRP composites layer can be used to improving flexural and shear capacities and also to provide confinement and ductility to compression members. The increase in strength and ductility strongly depends on many parameters amongst the length and the amount and configuration of FRP laminates [3-5].

The carrying capacity, failure patterns and the FRP material utilizations of the reinforced concrete structure were largely determined by the bonding performance between FRP and concrete [6].

Some researches about the failure process of the FRP reinforced concrete structure had been done by authors [7-8]. On base of the preliminary research work, the effect of FRP sheet

*Corresponding author:zhang_juanxia@126.com 
length on the failure mode was studied through three-point bending test of different samples with different FRP sheet length of concrete beams and plain concrete beam. The test data and investigations reported herein would provide valuable information for both research and design applications.

\section{Experiment Research}

\subsection{General Situation of the Experiment}

The test samples have been shown in Fig.1 and Fig.2. Eight specimens consist of two plain concrete beams, six FRP strengthened concrete beams with same thickness and width but different length of FRP sheet, were tested under three-point bending test by the microcomputer control electron universal testing machines.

The load is applied in the vertical direction with the displacement-controlled loading scheme. For the specimens, L1 indicates the FRP length of FRP reinforced concrete beam, B1 indicates plain concrete beam, L1,L2 and L3 indicates the FRP sheet length are $150 \mathrm{~mm}, 250 \mathrm{~mm}$, and $350 \mathrm{~mm}$, respectively. For the FB-L1-1 specimen, it indicates the first specimen (-1) with the FRP length of $150 \mathrm{~mm}(\mathrm{~L} 1)$. So do the other mark number.
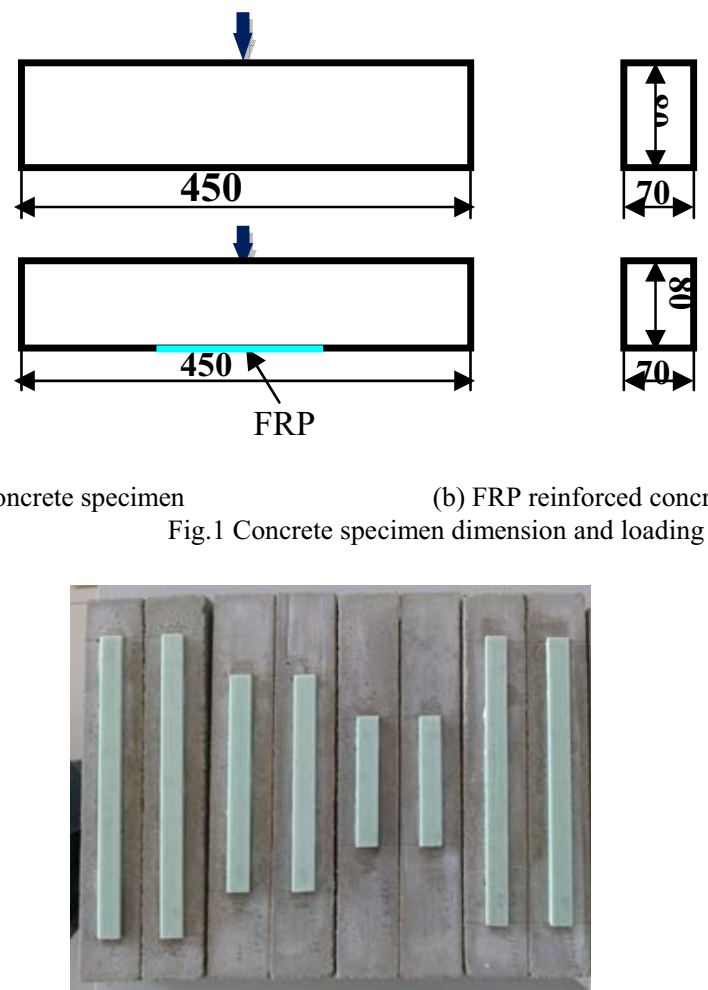

Fig.2 FRP reinforced concrete specimen 


\subsection{Analysis of Test Results}

\subsubsection{Failure Mode of Concrete Specimen}

The failure mode pictures of part plain concrete beam and FRP reinforced concrete beams have been shown in Fig.3. From the failure mode pictures, as shown in Fig.3, for the B1-1 specimen, it can be seen that one dominant flexural crack locally occurs at mid span in the bottom of the beam, and gradually expanding to the loading point with the increasing of load displacement during the experiment process. For the FB-L1-1 specimen, one dominant flexural crack locally occurs at the bottom of the beam near the end of the FRP sheet and from which the debonding initiates and propagates. For the FB-L2-2 and FB-L3-2 (FB-W1-2), one dominant flexural crack locally occurs at mid span and the debonding starts to propagate from the end of the FRP sheet. The FRP sheet length directly influences the failure mode of concrete beam.

In the experiments, the interfacial debonding easily propagate along the interfacial concrete layer due to the adhesive tensile strength being not enough, the maximum tensile strength value was not reached for all the specimens, so the tensile strength of FRP sheet was not fully utilized.

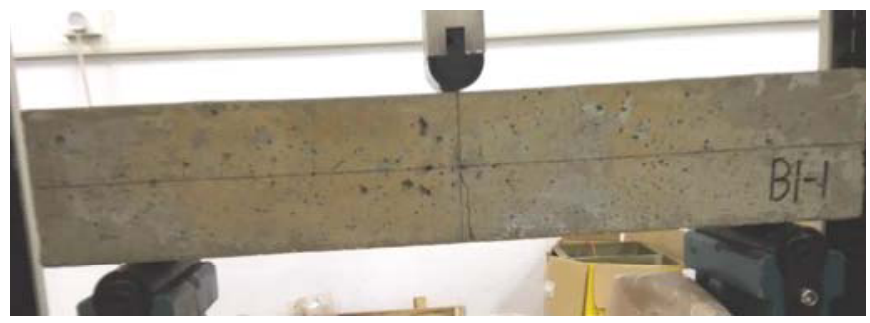

(a) Failure pattern of plain concrete beam

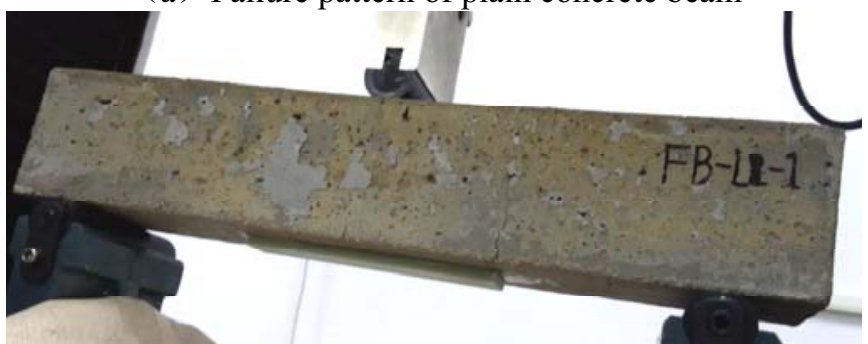

(b) Failure pattern of FB-L1 concrete specimen

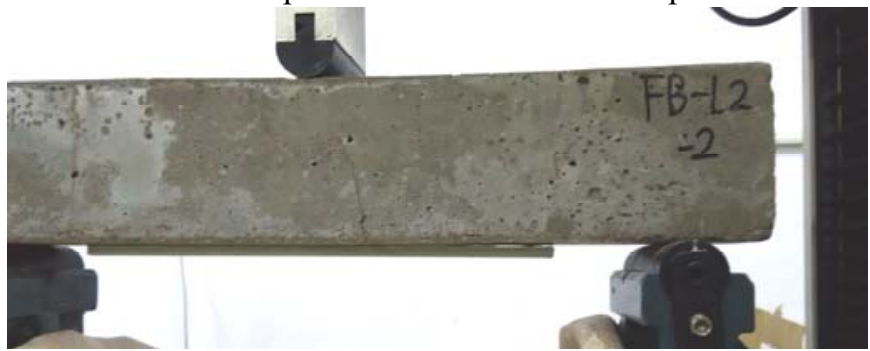

(c) Failure pattern of FB-L2concrete specimen 


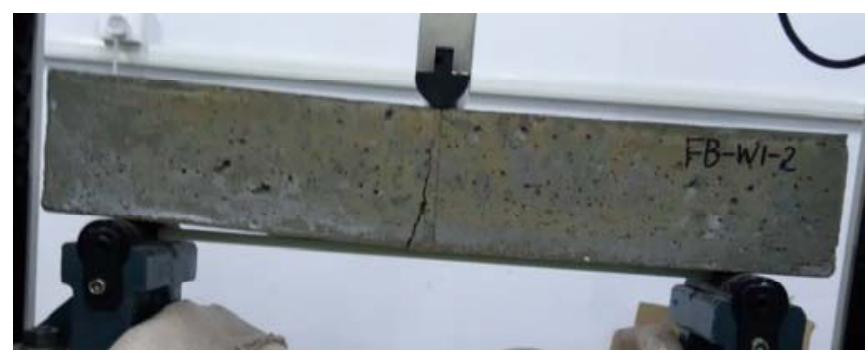

(d) Failure pattern of FB-L3 specimen

Fig.3 Failure pattern of the FRP reinforced concrete beam with different FRP sheet length and plain concrete beam

\subsubsection{Load-Displacement Curves}

The structural load-displacement curves obtained by the experiment for the FRP reinforced concrete specimens with different sheet length are compared in Fig.4. In the figures, Plain indicates the plain concrete specimen without FRP sheet, FB-L1, FB-L2, FB-L3 indicate the sheet length reinforced on the concrete beam are $150 \mathrm{~mm}, 250 \mathrm{~mm}$, $350 \mathrm{~mm}$, respectively. During the initial loading phase of the failure process, the stress and strain of the FRP sheet are small and the external loading predominantly supported by the concrete. It can be found that there is no difference for the initial load of the four specimens; in other words, there is no influence on the specimen load for the reinforcement mechanical properties, but the ultimate load and the ultimate strain of the specimen is increased with the increasing of the FRP sheet length, it due to the different strengthening effects to the beams of the FRP sheet length.

Obviously, the maximum tensile strength value was not reached for all the specimens; it due to the adhesive layer between the concrete and FRP sheet was not being strong enough and the existing of the induced adhesive shear and peel-off stresses in the bond between the FRP sheet and concrete.

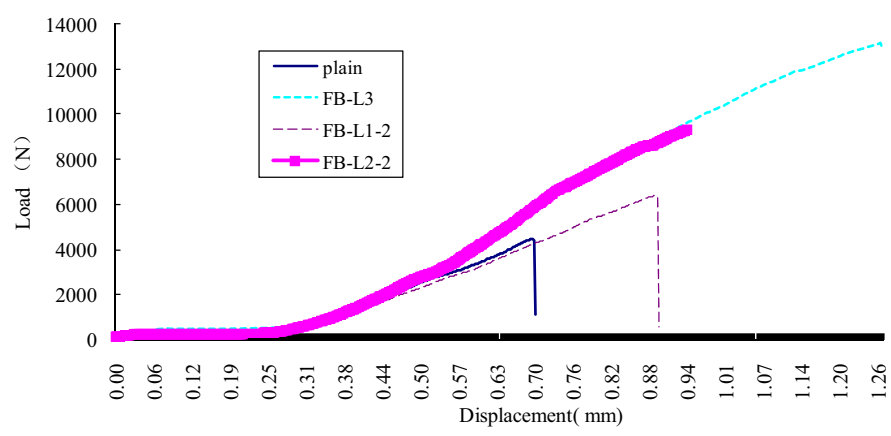

Fig.4 Load-displacement comparison curves with different FRP sheet length and plain concrete beam

\subsubsection{Comparison between Experimental Results and Numerical Results}

The RFPA3D (Realistic Failure Process Analysis) modeling of the beam model has been shown in Fig.5, it shows the ultimate failure mode for the plain concrete beam and FRP reinforced concrete beam, respectively. The detailed descriptions about the FRPA had been given in [9-10].The load is applied in the vertical direction with the displacement-controlled 
loading scheme. For the plain concrete beam, only one dominant flexural crack locally occurs at mid span, but for the FRP sheet reinforced concrete beam, more microcracks produced on the concrete adjacent to bond surface, and a secondary diagonal shear or flexural crack occurs beside the first flexural concrete crack at mid-span. It showed that the numerical simulation result is perfect due to the adhesive layer between the concrete and FRP sheet was strong enough, but for the experimental results, the debonding mainly occurs due to the weak bonding layer, as shown in Fig.4.

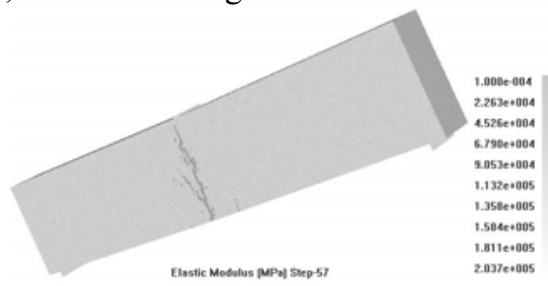

(a) the plain concrete beam

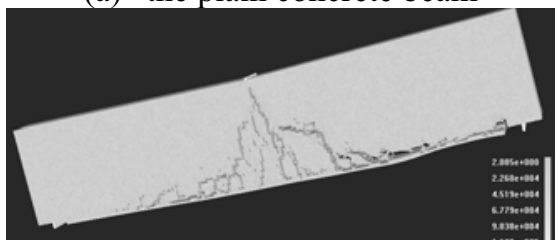

(b) the FRP reinforced concrete beam

Fig. 5 the failure mode pictures for the plain concrete beam and FRP reinforced concrete beam simulated by numerical test

\section{Conclusions}

In this paper, the failure mode and the maximum deflection of the plain concrete beam and FRP reinforced concrete beam with different FRP sheet length were analyzed by experiments. It can be found that there is no influence on the load capacity of the plain concrete specimen and FRP reinforced concrete specimens initially, due to the load were being supported by the concrete. But the ultimate load capacity is increased with the increasing of the FRP sheet length. More microcracks produced on the concrete adjacent to bond surface with the increasing of the FRP sheet length. From the experiments and numerical simulation results, it can be concluded that the FRP sheet length is considered to be an important factor on the failure mode and load capacity. The best result of the FRP sheet was not achieved due to the adhesive layer between the concrete and FRP sheet was not strong enough, the debonding failure mode mainly occurs in the experiments.

\section{Acknowledgement}

The research is supported by the NSFC (Grant NO.51174208), the National Major Fundamental Research Program (973) (NO.2013CB227903) and the Fundamental Research Funds for the Central Universities (No. N120423003). The authors are grateful for these supports. 


\section{References}

1. J.G Teng, H Yuan, J.F Chen.International Journal of Solids and Structures, 2006,43: 5750- 5778.

2. Z.S Wu, J Yin. Engineering Fracture Mechanics, 2003, 70: 1339-1355.

3. R Z.Al-Zaid, A.Z I.Al-Negheimish, M. A. Al-Saawani, A. K.El-Sayed. Composites: Part B, 43(2012): 129-141.

4. T.Xu, Z.J He, C.A. Tang, W.C.Zhu, P.G.Ranjith. Finite elements in analysis and design. 2015, 93:30-41.

5. M Maalej, K.S Leong. Compos Sci Technol 2005:1148-58.

6. R. Sun, E.Sevillano, R.Perera. Compostite Structures, 2015, 25:374-387.

7. J.X Zhang, W.C Zhu, C.A Tang, X.Z Guo. Journal of Northeastern University (Natural Science ). 2011,32 (10) :1495-1498.

8. J.X Zhang, C.A Tang, W.C Zhu, Z.Z Liang, et al. Engineering mechanics, 2006,23(12): 143-147.

9. C.A Tang, W.C Zhu, Science Press, Beijing, China,2003.

10. J.X.Zhang, Doctor thesis, Shenyang,2006. 